\title{
LA-UR- $00-4688$
}

Approved for public release; distribution is unlimited.

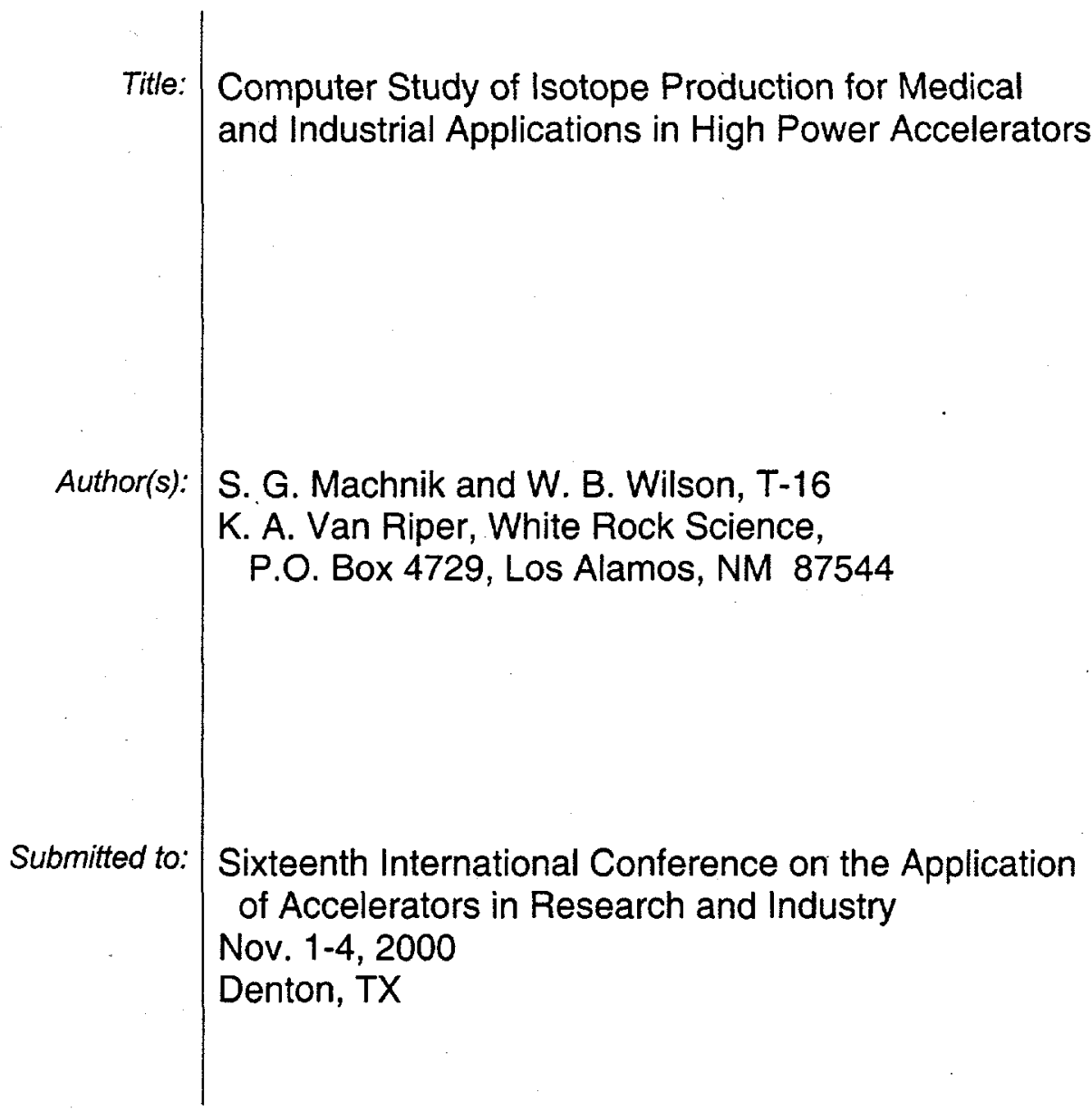

\section{Los Alamos}

\section{NATIONAL LABORATORY}

Los Alamos National Laboratory, an affirmative action/equal opportunity employer, is operated by the University of California for the U.S. Department of Energy under contract W-7405-ENG-36. By acceptance of this article, the publisher recognizes that the U.S. Government retains a nonexclusive, royalty-free license to publish or reproduce the published form of this contribution, or to ailow others to do so, for U.S. Govemment purposes. Los Alamos National Laboratory requests that the publisher identify this article as work performed under the auspices of the U.S. Department of Energy. Los Alamos National Laboratory strongly supports academic freedom and a researcher's right to publish; as an institution, however, the Laboratory does not endorse the viewpoint of a publication or guarantee its technical correctness. 


\section{DISCLAIMER}

This report was prepared as an account of work sponsored by an agency of the United States Government. Neither the United States Government nor any agency thereof, nor any of their employees, make any warranty, express or implied, or assumes any legal liability or responsibility for the accuracy, completeness, or usefulness of any information, apparatus, product, or process disclosed, or represents that its use would not infringe privately owned rights. Reference herein to any specific commercial product, process, or service by trade name, trademark, manufacturer, or otherwise does not necessarily constitute or imply its endorsement, recommendation, or favoring by the United States Government or any agency thereof. The views and opinions of authors expressed herein do not necessarily state or reflect those of the United States Government or any agency thereof. 


\section{DISCLAIMER}

Portions of this document may be illegible in electronic image products. Images are produced from the best available original document. 


\title{
Computer Study of Isotope Production for Medical and Industrial Applications in High Power Accelerators
}

\author{
S. G. Mashnik and W.B. Wilson \\ T-16, Theoretical Division, LANL, Los Alamos, NM 87545 \\ tel.: 505-667-9946,e-mail: mashnik@t2y.lanl.gov \\ K. A. Van Riper \\ White Rock Science, PO Box 4729, Los Alamos, NM 87544
}

\section{ABSTRACT}

Methods for radionuclide production calculation in a high power proton accelerator have been developed and applied to study production of 22 isotopes. These methods are readily applicable both to accelerator and reactor environments and to the production of other radioactive and stable isotopes. We have also developed methods for evaluating cross sections from a wide variety of sources into a single cross section set and have produced an evaluated library covering about a third of all natural elements that may be expanded to other reactions. A 684 page detailed report on this study, with 37 tables and 264 color figures is available on the Web at http://t2.lanl.gov/publications/.

\section{INTRODUCTION}

The widespread use of radionuclides in medical and industrial applications is steadily increasing, leading suppliers to seek out new production facilities. A reliable supply chain is necessary to both encourage new applications and to replace aging production sources. The United States, in particular, faces a domestic production shortfall. It has been a policy of this country to import radioisotopes from Canada and other countries. The lack of a reliable supply has led to supply problems at times that could be ameliorated by a domestic production facility.

Among the possibilities for radionuclide production are high power accelerators, either purpose built or alongside existing applications. As an example of the latter, a recent study by the Medical University of South Carolina [1] discussed the production of medical radioisotopes at the proposed Accelerator Production of Tritium Facility (APT) [2].

We have undertaken a study to see to what extent existing nuclear data models are applicable to calculations of radionuclide production in a high energy, high power environment. We chose the APT target/blanket assembly as a typical environment in which to study isotope production. In a previous report [3], we considered the production of two radioisotopes $-{ }^{18} \mathrm{~F}$ and ${ }^{131} \mathrm{I}$
- at two locations in the APT blanket. We have extended that study to look at the production rates of 22 isotopes in nearly 500 locations throughout the APT target and blanket. In addition to the 100 milliamp 1.7 GeV proton beam energy assumed in the previous study, we also treat beam energies of $1.0,1.2,1.4,1.6$, and $1.8 \mathrm{GeV}$ (all at 100 milliamps).

It should be noted that we have chosen the APT accelerator for our study as an example with which to demonstrate the possibility of production of radioisotopes at such a facility. Radioisotopes can be produced also at other high power accelerators, projected for the Accelerator Transmutation of nuclear Wastes (ATW) or for Neutron Spallation Source (SNS) facilities, as well as at nuclear reactors. Our computational method is not limited to a particular facility and can be used to study production of radioactive and stable isotopes at any accelerator or reactor. For practical reasons, the emphasis of our present study is on radioisotopes.

We have prepared numerous figures and tables as part of this work. Space available in this paper prevents their inclusion here. Our 684 page detailed report on this study [4], with 37 tables and 264 color figures is available on the World Wide Web at http://t2.lanl.gov/publications/ and a limited number of hard copies may be available from the authors.

\section{APT Modeling and Flux Tallies}

Figure 1 is a 3 -dimensional rendering of a computer model of the target/blanket assembly. The model is based on the Todosow geometry with a $16 \mathrm{~cm} \times 160$ $\mathrm{cm}$ beam area. The beam enters the assembly through the window on the right. The beam strikes tungstendominated ladders in the center of the assembly; the position of these ladders correspond to the pipes extending from the manifolds. The lateral blankets extend to either side of the beam line and ladder area. The downstream blanket encompasses the region to the left of the ladder region, while the upstream blanket is the narrow area between the entrance window and the 
ladder region.

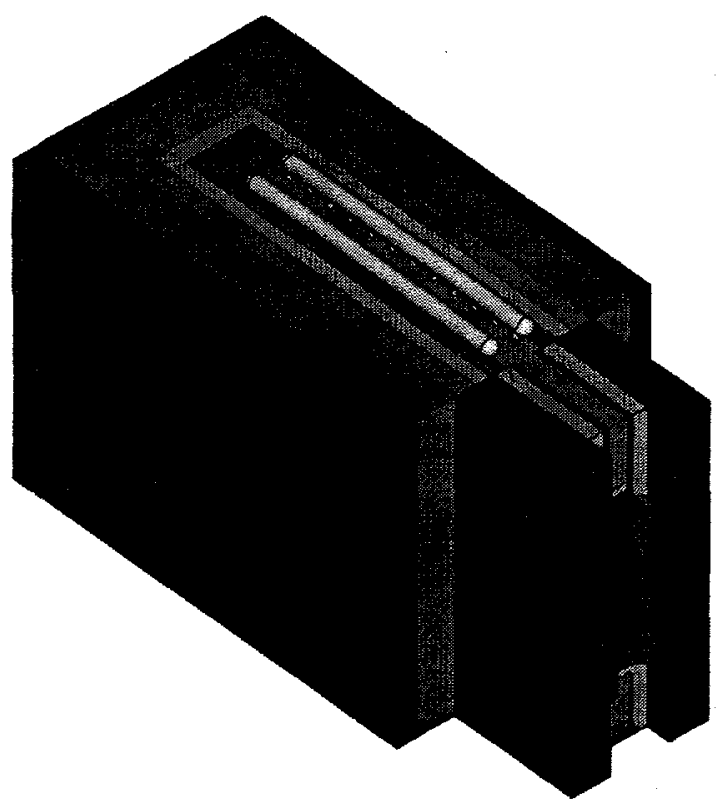

Figure 1: APT target/blanket assembly.

Tally Locations. Subdivision of cells in the upstream, downstream, and lateral blanket regions and in the beam cavity between ladders yielded approximately 183 cells in which the fluxes were tallied. Figure 2 shows the cell locations in a slice in the $\mathrm{X}-\mathrm{Z}$ plane through the middle of the target model. We did not tally fluxes in the ladders, nor in the coolant pipes.

Vertical Segments. We segmented the tallies into five equally spaced vertical segments. Color figures with cross section through the upstream blanket, showing the segmenting and further details may by found in our comprehensive report [4].

The fluxes, and hence production rates, were greatest in the middle segment, decreasing towards the top and bottom. Unless otherwise stated, the results presented here are for the middle segment.

Locations for Detailed Results. We present detailed summaries of the production rates at four locations in our report [4].

For each reaction, we found the cell with the maximum rate over our entire set of tallies, and the cell with the maximum rate over all tallies excluding the beam cavity cells.

We did not model any fixtures, such as irradiation tubes, that would be required to produce radioisotopes in any location. Our results thus assume any such fixtures would have no effect on the fluxes.

Spectrum plots of the neutron and proton fluxes in each segment of the four selected locations are given in our detailed report [4].

Flux Color Contours on Planes. We prepared a variation of the target geometry for display of the fluxes (and production rates) as color-coded contours on a plane [4]. We introduced 5 planes to represent the

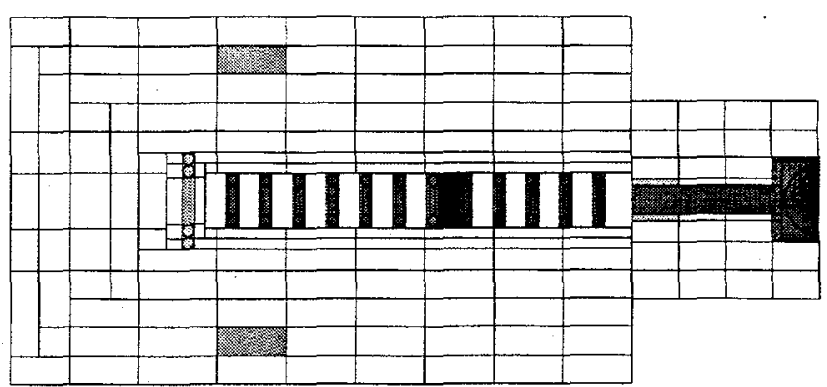

Figure 2: A slice through the middle of the APT target/blanket assembly showing cells where tallies were taken.

5 vertical segments; the vertical position of the plane lies at the center of the corresponding segment. Each plane thus represents the flux averaged over a segment.

Figure 3 shows a contour plot of the neutron flux for a $1.0 \mathrm{GeV}$ beam energy. The detailed Web report [4] includes similar (color) plots for neutron and proton flux contours at the 6 energies we consider.

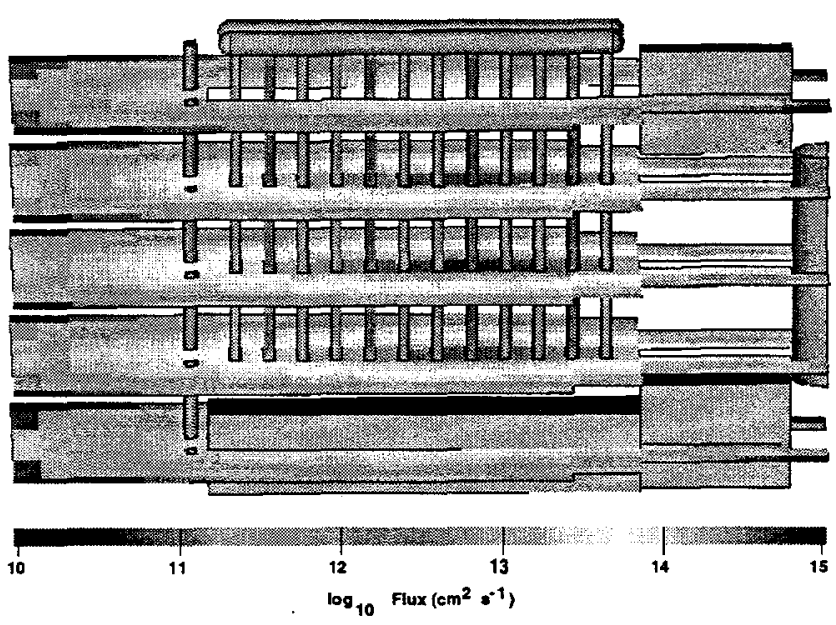

Figure 3: Contour plot of the neutron flux at a beam energy of $1.0 \mathrm{GeV}$.

\section{Cross Section Evaluations}

At present, neither available experimental data nor any of the current models or phenomenological systematics can be used alone to produce a reliable evaluated activation cross section library covering a large range of target nuclides and incident energies. Therefore, we chose to create our evaluated library [5] by constructing excitation functions using all available experimental data along with calculations using some of the more reliable codes, employing each of these sources in the regions of targets and incident energies where they are most applicable. When we have reliable experimental data, they, rather than model results, are taken as the highest priority for our approximation. Wherever possible, we attempted to construct a smooth transition from one data source to another. 
The recent International Code Comparisons for Intermediate Energy Nuclear Data organized by NEA/OECD at Paris [6], our own comprehensive benchmarks $[3,5,4,7,8]$, several studies by Titarenko et al. [9] and the recent Ph.D. thesis by Batyaev [10], specially dedicated to benchmark currently available models and codes, have shown that a modified version of the Cascade-Exciton model (CEM) [11] as realized in the code CEM95 [12] and LAHET code system [13] generally have the best predictive powers for spallation reactions at energies above $100 \mathrm{MeV}$ as compared to other available models. Therefore, we choose CEM95, the recently improved version of the CEM code [14], and LAHET (version 2.83) above $100 \mathrm{MeV}$ to evaluate the required cross sections. The same benchmarks have shown that at lower energies, the HMS-ALICE code [15] most accurately reproduces experimental results as compared with other models. We therefore use the activation library calculated by $M$. B. Chadwick [8] with HMS-ALICE for protons below $100 \mathrm{MeV}$ and neutrons between 20 and $100 \mathrm{MeV}$. In the overlapping region, between 100 and $150 \mathrm{MeV}$, we use both HMS-ALICE and CEM95 and/or LAHET results. For neutrons below $20 \mathrm{MeV}$, we consider the data of the European Activation File EAF-97, Rev. 1 [16, 17] with some recent improvements by M. Herman [18], to be the most accurate results available; therefore we use them here.

Measured cross-section data from our compilation described in [5], when available, are included together with theoretical results and are used to evaluate cross sections for study.

Results for 308 proton-induced and 342 neutroninduced evaluated cross sections are shown in 109 color figures on the Web, in our detailed report [4].

\section{Production Rate Calculations}

We consider production rates for the following 22 end product nuclides of medical importance [1]: ${ }^{18} \mathrm{~F},{ }^{35} \mathrm{~S}$, ${ }^{89} \mathrm{Sr},{ }^{133} \mathrm{Xe},{ }^{22} \mathrm{Na},{ }^{67} \mathrm{Cu},{ }^{89} \mathrm{Zr},{ }^{131} \mathrm{Cs},{ }^{32} \mathrm{Si},{ }^{32} \mathrm{P},{ }^{67} \mathrm{Ga}$, ${ }^{95} \mathrm{Zr},{ }^{137} \mathrm{Cs},{ }^{32} \mathrm{P},{ }^{68} \mathrm{Ga},{ }^{95} \mathrm{Nb},{ }^{193 m} \mathrm{Pt},{ }^{33} \mathrm{P},{ }^{68} \mathrm{Ge},{ }^{68} \mathrm{Ga}$, ${ }^{131} \mathrm{I}$, and ${ }^{195 m} \mathrm{Pt}$. To produce these nuclides, we calculated neutron and proton reactions on 70 stable, naturally occurring isotopes of 25 elements in the neighborhood of the targets investigated (See details in [4]). ${ }^{138,139} \mathrm{La}$, For each reaction, we 1) constructed a continuous energy representation of the cross section from the evaluation tables; 2)-formed a flux-weighted average cross section for each particle flux at each location; 3) computed the one-hour irradiation end product $P$ production rate per gram of target to each target nuclide/reaction product $p$ radionuclide combination; 4) formed the one hour irradiation production rate per gram of target nuclide or naturally occurring element.

The flux-weighted cross section $\sigma_{t p}$ for each target $t$ and reaction product $p$ is found by

$$
\sigma_{t p}=\frac{\int_{0}^{\infty} \phi(E) \sigma_{t p}(E) d E}{\int_{0}^{\infty} \phi(E) d E}=\frac{\sigma_{t p} \Phi}{\Phi}
$$

The cross section $\sigma_{t P}$ leading to end product $P$ is taken as the sum of all cross sections for the direct production of $P$ and products $p$ decaying to $P$. The cross section $\sigma_{Z P}$ for element $Z$ leading to end product $P$ is obtained as the natural-abundance-weighted sum of the cross sections $\sigma_{t P}$ of the various naturally occurring target nuclides of the element.

The production rate $R_{t P}(\mathrm{Ci} / \mathrm{g}-\mathrm{hr}$ ) for each target $t$ - end product $P$ combination is

$$
R_{t P}=N_{t} \sigma_{t P} \Phi\left[1-\exp \left(-\lambda_{p} T\right)\right]
$$

where $\lambda_{p}$ is the decay constant $\left(\mathrm{s}^{-1}\right)$ of end product $P, T=3600$ s corresponds to a one-hour irradiation, $N_{t}=N_{0} / A_{t}$ is the atom density (atoms $/ \mathrm{g}$ ) of the target material, $N_{0}$ is Avogadro's number $\left(6.022 \times 10^{23}\right.$ atoms/mole), and $A_{t}$ is the atomic weight of the target. $A_{t}$ is taken as the integer mass number for isotopic targets and as the atomic weight for the elements.

\section{Isotope Production Rates}

Our Web report [4] includes complete tables for the production rates all isotopes studied, for all beam energies. Also, on the Web are tables that gives detail of these production rates, including the flux-averaged cross sections and production rates for intermediate products, and color contour plots of production rates for natural element target at a beam energy of $1.7 \mathrm{GeV}$.

\section{Dependence on Position and Beam Energy}

We selected three groups of cells, all in the middle segment, to explore the dependence of the production rates on position in the target/blanket assembly and on the beam energy. Figures showing the variation of production rates with beam energy and distance from natural element targets are included in our Web report. The rates increase with beam energy, by between factors of 1.5 and 5 from beam energies of 1.0 to $1.8 \mathrm{GeV}$. The downstream cells closest to the beam cavity are less sensitive to beam energy than those further downstream. There is less spread in the beam energy dependence in the lateral cells than in the other groups. Within the beam cavity, the rates peak at a distance of $140 \mathrm{~cm}$. The rates decrease exponentially with distance into the lateral blanket. Downstream of the first few cells in the downstream blanket, the rates also decrease exponentially with distance into the downstream blanket. 


\section{Summary}

We have characterized the radiation environment in a high power proton accelerator and developed methods for radionuclide production calculations. These methods are readily applicable to accelerator, and reactor, environments other than the particular model we considered and to the production of other radioactive and stable isotopes. We have also developed methods for evaluation cross sections from a wide variety of sources into a single cross section set. These methods also are applicable to an expanded set of reactions.

Commenting on the feasibility and economic viability of the production of any particular isotope is beyond the scope of this work. Such information, which must come from experts in the radionuclide arena, will be a vital ingredient in choosing which cross sections should be subjected to greater scrutiny.

This study was partially supported by the U.S. Department of Energy.

\section{REFERENCES}

[1] Spicer, K. M., Baron, S., Frey, G. D., et al., "Evaluation of Medical Radionuclide Production with the Accelerator Production of Tritium (APT) Facility," Medical University of South Carolina final report (July 15, 1997).

[2] Browne, J. C., Anderson, J. L., Cappiello, et al., "Status of the Accelerator Production of Tritium (APT) Project," in The Savannah River Accelerator Project and Complementary Spallation Neutron Sources, edited by F. T. Avignone and T. A. Gabriel, World Scientific, Singapore, 1998, pp. 1436 .

[3] Van Riper, K. A., Mashnik, S. G., Chadwick, M. B., et al., "APT Medical Isotope Production Study: ${ }^{18} \mathrm{~F}$ and ${ }^{131}$ I Production," Los Alamos National Laboratory Report LA-UR-97-5068 (1997); hppt://t2.lanl.lanl.gov/publications/.

[4] Van Riper, K. A., Mashnik, S. G., and Wilson, W. B., "Study of Isotope Production in High Power Accelerator," Los Alamos National Laboratory report LA-UR-98-5379 (1998); hppt://t2.lanl.lanl.gov/publications/.

[5] Mashnik, S. G., Sierk, A. J., Van Riper, K. A., and Wilson, W. B.,. "Production and Validation of Isotope Production Cross Section Library for Neutrons and Protons to $1.7 \mathrm{GeV}$," in Simulating Accelerator Radiation Environments (SARE4), edited by T. A. Gabriel, ORNL, 1999, pp. 151-162; E-print nucl-th/9812071.

[6] Blann, M., Gruppelar, H., Nagel, P., and Rodens, J., International Code Comparison for Intermediate Energy Nuclear Data, NEA OECD, Paris, 1994; Michel R., and Nagel, P., International Codes and Model Intercomparison for Intermediate Energy Activation Yields, NSC/DOC(97)-1, OECD, Paris (1997); http://www.nea.fr/html/science/pt/ieay.

[7] Mashnik, S. G., Sierk, A. J., Bersillon, O., and Gabriel, T. A., Nucl. Instr. Meth. A 414, 68-72 (1998).

[8] Koning, A. J., Chadwick, M. B., MacFarlane, R. E., Mashnik, S. G., and Wilson, W. B., "Neutron and Proton Transmutation-Activation Libraries to $150 \mathrm{MeV}$ for Application in AcceleratorDriven Systems and Radioactive Ion Beam TargetDesign Studies," ECN Report ECN-R-98-012, Petten (1998).

[9] Titarenko, Yu. E., Shvedov, O. V., Igumnov, M. M., et al., Nucl. Instr. Meth. A 414, 73-99 (1998); E-prints nucl-ex/0008011 and nucl-ex/0008012.

[10] Batyaev, V. F., Ph.D. thesis, ITEP, Moscow, 1999.

[11] Gudima, K. K., Mashnik, S. G., and Toneev, V. D., Nucl. Phys. A 401, 329-361 (1983).

[12] Mashnik, S. G., "User Manual for the Code CEM95," JINR, Dubna (1995), OECD NEA Data Bank, Paris, France (1995); RSIC-PSR-357, Oak Ridge, 1995; http://www.nea.fr/abs/html/iaea1247.html.

[13] Prael, R. E., and Lichtenstein, H., "User Guide to LCS: The LAHET Code System," Los Alamos National Laboratory report LA-UR-89-3014 (1989).

[14] Mashnik, S. G., and Sierk, A. J., "Improved Cascade-Exciton Model of Nuclear Reactions," in Simulating Accelerator Radiation Environments (SARE4), edited by T. A. Gabriel, ORNL, 1999, pp. 29-51; E-print nucl-th/9812069.

[15] Blann, M., Phys. Rev. C 54, 1341-1349 (1996); Blann, M., and Chadwick, M. B., Phys. Rev. C 57, 233-243 (1998).

[16] Muir, D. W., and Koning, A. J., "Validation of the ECNAF Neutron Activation Cross-Section Library," in Accelerator-Driven Transmutation Technologies and Applications, edited by $\mathrm{H}$. Condé, Uppsala University Press, 1997, vol. 1, pp. 469-475.

[17] Sublet, J.-Ch., Kopecky, J., Forrest, R. A., and Nierop, D., "The European Activation File: EAF97 Report file-Rev. 1," UKAEA, Culham, Abigdon, Oxfordshire OX $14 \mathrm{~B}$, United Kingdom (1997).

[18] Herman, M., "LANL Update II of the ECNAF Neutron Activation Cross-Section Library," Los Alamos National Laboratory report LA-UR-964914 (1996). 